\title{
Correction to: investigation on the mitigation of environmental harmful emissions by incorporating nanoparticles to biofuel water nano emulsion in low heat rejection engine
}

\author{
P. V. Elumalai ${ }^{1} \cdot$ C. Sivakandhan ${ }^{2} \cdot$ M. Parthasarathy ${ }^{3} \cdot$ S. Mohamed Iqbal ${ }^{4} \cdot$ M. $^{\text {Arunkumar }}{ }^{5}$ \\ Published online: 12 March 2021 \\ (C) Springer-Verlag GmbH Germany, part of Springer Nature 2021
}

\section{Correction to: Heat and Mass Transfer} https://doi.org/10.1007/s00231-021-03028-7

The names of the authors were incorrect.

1. Parathasarathy should be Parthasarathy.

2. Mohamad Iqubal corrected name in the proof Mohamed Iqbal

The original article has been corrected.

Publisher's note Springer Nature remains neutral with regard to jurisdictional claims in published maps and institutional affiliations.

The online version of the original article can be found at https://doi.org/ 10.1007/s00231-021-03028-7

$\triangle$ P. V. Elumalai

elumalaimech89@gmail.com; elumalai@aec.edu.in

1 Department of Mechanical Engineering, Aditya Engineering

College, Surampalem, East Godavari, Andhra Pradesh 533437, India

2 Department of Mechanical Engineering, Nadar Saraswathi College of Engineering and Technology, Theni, Tamil Nadu 625531, India

3 Department of Automobile Engineering, Vel Tech Rangarajan Dr. Sagunthala R\&D Institute of Science and Technology, Avadi, Tamil Nadu, India

4 Department of Mechanical Engineering, Vel Tech Rangarajan Dr. Sagunthala R\&D Institute of Science and Technology, Avadi, Tamil Nadu, India

5 Department of Agriculture Engineering, Sri Shakthi Institute of Engineering and Technology, Coimbatore, Tamil Nadu, India 